\title{
Long-term effectiveness and cost-effectiveness of smoking cessation interventions in patients with COPD
}

\author{
Martine Hoogendoorn, ${ }^{1}$ Talitha L Feenstra, ${ }^{2,3}$ Rudolf T Hoogenveen, ${ }^{2}$ \\ Maureen P M H Rutten-van Mölken
}

- Supplementary data are published online only. To view these files please visit the journal online (http://thorax.bmj. com)

${ }^{1}$ Institute for Medical Technology Assessment (iMTA), Erasmus University, Rotterdam, The Netherlands

${ }^{2}$ National Institute of Public Health and the Environment (RIVM), Bilthoven, The Netherlands

${ }^{3}$ Department of Epidemiology, University Medical Centre Groningen, Groningen, The Netherlands

Correspondence to M Hoogendoorn, Institute for Medical Technology Assessment, Erasmus University, P 0 Box 1738, 3000 DR Rotterdam, The Netherlands; hoogendoorn@bmg.eur.nl

Received 20 November 2009 Accepted 4 May 2010

\author{
ABSTRACT \\ Background The aim of this study was to estimate the \\ long-term (cost-) effectiveness of smoking cessation \\ interventions for patients with chronic obstructive \\ pulmonary disease (COPD).
}

Methods A systematic review was performed of randomised controlled trials on smoking cessation interventions in patients with COPD reporting 12-month biochemical validated abstinence rates. The different interventions were grouped into four categories: usual care, minimal counselling, intensive counselling and intensive counselling + pharmacotherapy ('pharmacotherapy'). For each category the average 12-month continuous abstinence rate and intervention costs were estimated. A dynamic population model for COPD was used to project the long-term (cost-) effectiveness (25 years) of 1-year implementation of the interventions for $50 \%$ of the patients with COPD who smoked compared with usual care. Uncertainty and one-way sensitivity analyses were performed for variations in the calculation of the abstinence rates, the type of projection, intervention costs and discount rates.

Results Nine studies were selected. The average 12-month continuous abstinence rates were estimated to be $1.4 \%$ for usual care, $2.6 \%$ for minimal counselling, $6.0 \%$ for intensive counselling and $12.3 \%$ for pharmacotherapy. Compared with usual care, the costs per quality-adjusted life year (OALY) gained for minimal counselling, intensive counselling and pharmacotherapy were $€ 16900$, $€ 8200$ and $€ 2400$, respectively. The results were most sensitive to variations in the estimation of the abstinence rates and discount rates. Conclusion Compared with usual care, intensive counselling and pharmacotherapy resulted in low costs per QALY gained with ratios comparable to results for smoking cessation in the general population. Compared with intensive counselling, pharmacotherapy was cost saving and dominated the other interventions.

\section{INTRODUCTION}

Smoking cessation is still the most important intervention to slow down the disease progression of chronic obstructive pulmonary disease (COPD). ${ }^{1-3}$ It decreases the annual decline in lung function, ${ }^{4}$ reduces symptoms of cough and sputum, improves health status and reduces exacerbations of COPD. ${ }^{5}$ Because of the strong association between use of healthcare services and disease severity, ${ }^{6}$ slowing down disease progression is likely to reduce annual COPD-related healthcare costs.
Current treatment guidelines recommend that all patients with COPD who smoke should be offered the most intensive smoking cessation intervention feasible. ${ }^{7} 8$ A review of five smoking cessation interventions offered to patients with COPD by Wagena et al showed that only pharmacotherapy combined with intensive counselling seemed to be effective in this patient group. The effects of less intensive strategies did not reach statistical significance. $^{9}$ A more recent review concluded that counselling plus nicotine replacement therapy (NRT) had the greatest effect on prolonged abstinence rates in patients with COPD who smoke. ${ }^{10}$ Although almost all smoking cessation interventions targeted at smokers in the general population are cost-effective, ${ }^{11} 12$ little is known about the cost-effectiveness of smoking cessation interventions offered to patients who already have a smoking-related disease like COPD. Since information on the short-term cost-effectiveness of these interventions in COPD is already scarce, information on the long-term costeffectiveness is virtually absent. It is, however, highly relevant to know the long-term cost-effectiveness because the health benefits are small in the first year after the intervention but will continue to increase over time.

The aim of this study was to estimate the impact of smoking cessation interventions offered to patients with COPD on the future burden of COPD using a previously published dynamic populationbased model of COPD disease progression. ${ }^{13}$

\section{METHODS}

\section{Study selection}

All randomised controlled trials published in English investigating the effectiveness of a smoking cessation intervention in patients with COPD confirmed by spirometry or physician diagnosis were included if the follow-up was at least 12 months. The smoking cessation intervention or therapy had to be the primary intervention and not part of a disease management or education programme and abstinence of smoking had to be biochemically validated.

\section{Search strategy}

We performed a literature search in MEDLINE using the following MeSH headings or words in the title or abstract: COPD or 'chronic obstructive pulmonary disease' or 'chronic bronchitis' in combination with smoking, tobacco, nicotine or smok* or nicotin* and one of the following terms: smoking cessation or tobacco use or quit* or stop* 
or cessat* or abstin* or abstain*. The search was performed in February 2009 and was limited to randomised controlled trials published in English. We also searched the reference lists of retrieved articles and checked the systematic reviews for further references. If the search in MEDLINE resulted in studies reporting 6-month results, but the authors were aware of other publications in which the 12-month results were presented, the study was included.

\section{Methodological quality}

The methodological quality of the selected studies was evaluated using the Jadad scale and the Delphi list. ${ }^{14} 15$ The Jadad scale consists of five questions with respect to randomisation and blinding. Each positive answer to a question was valued with 1 and a negative answer with 0 , resulting in a sum score ranging from 0 to $5 .{ }^{14}$ The Delphi list consists of nine aspects regarding randomisation, study population, blinding and presentation of results. Possible answers were scored as 1 point ('yes') or 0 points ('no' or 'don't know'), resulting in a sum score ranging from 0 to 9. ${ }^{15}$ Both scores were assigned independently by two reviewers ( $\mathrm{MH}$ and TF/MRvM). Points of disagreement were discussed until consensus was reached. Both scores were used in combination to assess the methodological quality of the studies.

\section{Combination of abstinence rates and intervention costs}

The interventions performed in the different arms of the selected trials were grouped into four categories: (1) care as usual-defined as no counselling or pharmacotherapy or any other type of smoking intervention offered as part of the trial ('usual care'); (2) minimal or brief counselling $<90 \mathrm{~min}$ in total ('minimal counselling'); (3) intensive counselling $\geq 90 \mathrm{~min}$ without pharmacotherapy ('intensive counselling'); and (4) intensive counselling in combination with any type of pharmacotherapy ('pharmacotherapy'). Interventions offering pharmacotherapy on a non-compulsory basis were included in the category with pharmacotherapy if this was used by $>50 \%$ of the patients. Patients in the placebo arms of drug trials often received some form of counselling and were therefore grouped into the categories 'minimal counselling' or 'intensive counselling' depending on the duration of counselling. For our model calculations we needed absolute quit rates for at least one of the four intervention categories. We therefore used random effect meta-analysis ${ }^{16}$ to account for study heterogeneity and estimated mean abstinence rates for all four categories. The rates were calculated separately for 12 months continuous abstinence and 12 months point prevalence abstinence; 12 months continuous abstinence was defined as biochemical validated abstinence at all measurements up to 12 months including the 12-month measurement and 12 months point prevalence abstinence was defined as biochemical validated abstinence at 12 months. We recalculated the abstinence rates of the intention-to-treat population assuming subjects with missing data to be smokers when this was not done in the main analysis of the article.

For studies providing sufficient details about the intervention, the costs of the intervention were estimated using Dutch unit costs for the year 2007. Based on these estimates the average intervention costs for all four intervention categories were calculated as the weighted means over the studies using the numbers of patients as weights.

\section{Model}

A dynamic population model for COPD was used to estimate the impact of increased implementation of smoking cessation interventions compared with usual care. ${ }^{13}$ The model is representative for the total Dutch COPD population (306000 patients in 2000) and is dynamic because changes in the population such as birth, mortality, ageing and changing smoking patterns in the population are taken into account. The model distinguishes six states: no COPD, four COPD severity stages (mild, moderate, severe and very severe COPD based on the GOLD classification ${ }^{8}$ ) and dead. The prevalence of COPD for the first year of simulation was distributed over the four COPD severity stages according to the observed severity distribution of physician-diagnosed patients in the Netherlands. ${ }^{17}$ For each following year the model simulates the changes in the number of patients with COPD, the severity distribution and annual COPD-related healthcare costs due to incidence, mortality and disease progression (ie, annual decline in forced expiratory volume in $1 \mathrm{~s}\left(\mathrm{FEV}_{1}\right)$ percentage predicted). Incidence, mortality and disease progression are specified by gender, age, smoking status and COPD disease severity. COPD-related healthcare costs are specified by gender, age and COPD severity. The most important input parameters of the model are shown in table 1. An extensive description of the model can be found elsewhere ${ }^{13}$ and is summarised in the online supplement. The model can be used for projections of the Dutch COPD population over time but, more importantly, to evaluate the long-term costs and health benefits of interventions as was done for this study. The effects of smoking cessation were modelled as a one-time increase in $\mathrm{FEV}_{1}$ percentage predicted in the year of smoking cessation followed by a lower annual decline in $\mathrm{FEV}_{1}$ percentage predicted based on the Lung Health Study ${ }^{4}$ and reduced mortality due to COPD and other smoking-related diseases. The implementation of smoking cessation interventions for patients with COPD was modelled by replacing the smoking cessation rates of usual care by the higher smoking cessation rates of the intervention for a certain period of time for a certain (part of) the COPD population. A higher cessation rate compared with usual care results in more patients with COPD quitting smoking, slower progression to worse COPD severity stages, less mortality and a reduction in COPD-related healthcare costs. The model uses 12-month abstinence rates and accounts for annual probabilities to relapse in former smokers, so former smokers may start smoking again $>1$ year after quitting. ${ }^{13}$

Table 1 Main input parameters of the COPD disease progression model $^{13}$

\begin{tabular}{|c|c|c|c|c|}
\hline & $\begin{array}{l}\text { Mild } \\
\text { COPD }\end{array}$ & $\begin{array}{l}\text { Moderate } \\
\text { COPD }\end{array}$ & $\begin{array}{l}\text { Severe } \\
\text { COPD }\end{array}$ & $\begin{array}{l}\text { Very } \\
\text { severe } \\
\text { COPD }\end{array}$ \\
\hline $\begin{array}{l}\text { Prevalence per } 1000 \text { people in the general } \\
\text { population* }\end{array}$ & 5.1 & 10.7 & 3.0 & 0.5 \\
\hline $\begin{array}{l}\text { Incidence per } 1000 \text { people in the general } \\
\text { population* }\end{array}$ & 0.71 & 0.94 & 0.08 & 0.003 \\
\hline \multicolumn{5}{|l|}{ Annual decline in $\mathrm{FEV}_{1} \%$ predicted $\dagger$} \\
\hline Smokers & -1.13 & -1.50 & -1.84 & -2.13 \\
\hline Ex-smokers & -0.79 & -1.17 & -1.51 & -1.79 \\
\hline $\begin{array}{l}\text { One-time increase in } \mathrm{FEV}_{1} \% \text { predicted } \\
\text { associated with smoking cessation }\end{array}$ & 0.03 & 2.91 & 5.56 & 7.76 \\
\hline \multicolumn{5}{|l|}{$\begin{array}{l}\text { Total mortality per } 1000 \text { COPD patients in } \\
\text { a specific severity stage* }\end{array}$} \\
\hline Smokers & 61 & 73 & 91 & 114 \\
\hline Ex-smokers $\ddagger$ & 51 & 64 & 82 & 104 \\
\hline COPD-related healthcare costs $(€, 2007)$ & 318 & 700 & 2389 & 7847 \\
\hline EQ-5D utility weights ${ }^{18}$ & 0.8971 & 0.7551 & 0.7481 & 0.5493 \\
\hline
\end{tabular}

*Data from the year 2000, the first year of the simulation.

†Data presented as the average for men and women with a mean age of 68 years, the mean age of the total Dutch COPD population.

$¥$ Standardised for the gender, age and COPD severity distribution of the smokers. $\mathrm{COPD}$, chronic obstructive pulmonary disease; $\mathrm{FEV}_{1}$, forced expiratory volume in $1 \mathrm{~s}$. 


\section{Outcome parameters}

The long-term effectiveness of the interventions was expressed in terms of the cumulative number of life years and qualityadjusted life years (OALYs) gained and the cumulative reduction in mortality. OALYs were calculated by weighting life years for the quality of life during these years in each COPD severity stage using EQ-5D utility weights (table 1). The cumulative number of life years, OALYs and deaths over the entire time horizon was calculated as the sum of the annual number of patients alive, the annual number of OALYs and the annual number of deaths, respectively, discounting future outcomes. The cumulative COPD-related healthcare costs were calculated as the properly discounted sum of the annual COPD-related healthcare costs over the time horizon. Finally, the cost per (quality-adjusted) life year gained was calculated as the ratio of total intervention costs minus savings in COPD-related healthcare costs compared with usual care divided by the cumulative (quality-adjusted) life years gained compared with usual care.

\section{Base case analysis}

In the base case analysis we modelled the impact of offering minimal counselling, intensive counselling or pharmacotherapy to $50 \%$ of the Dutch patients with COPD who smoke $(76000$ patients) for 1 year compared with usual care; $50 \%$ was chosen because this percentage of patients with COPD who smoke reported a willingness to stop smoking within 6 months. ${ }^{19} 20$ The base case analysis was performed using the mean 12-month continuous abstinence rates as calculated in the meta-analysis. Analyses were performed from a healthcare perspective. Effects and costs were evaluated over a time horizon of 25 years and were discounted at $1.5 \%$ and $4 \%$, respectively, as recommended by the Dutch guidelines for pharmacoeconomic evaluations. ${ }^{21}$

\section{Uncertainty and sensitivity analyses}

The uncertainty around the outcomes due to the uncertainty around the calculated abstinence rates and intervention costs was assessed using the $95 \%$ lower and upper limits of the difference in the abstinence rate compared with usual care and the minimum and maximum estimates of the intervention costs. Furthermore, a series of one-way sensitivity analyses was performed to estimate the impact of the choice of input parameters on the outcomes. In the first sensitivity analysis the impact of using the 12 -month point prevalence rates was assessed. In the second analysis, effects and costs were not discounted. For our base case analyses we used absolute quit rates based on random effect meta-analysis. In the third sensitivity analysis we replaced these by estimating the OR of minimal counselling, intensive counselling and pharmacotherapy versus usual care using a network meta-analysis approach $^{22}$ and applied these ORs to the average 12-month continuous abstinence rate for usual care. In the fourth sensitivity analysis the model was run for the cohort of Dutch patients with COPD present at the start of the simulations, assuming no new incidence of COPD. In contrast to the Netherlands, in many countries nortriptyline is not considered and/or used for pharmacological smoking cessation support because it is not registered as such. In the fifth sensitivity analysis we therefore estimated the outcomes for pharmacotherapy excluding the studies on nortriptyline.

\section{RESULTS}

The literature search identified 39 publications of which 26 were rejected in the first selection based on the title and abstract only.
The remaining 13 references were reviewed in full, resulting in the further exclusion of three papers. One reported abstinence rates which were not biochemically validated. The other two studies had a follow-up of 6 months and, to our knowledge, no other publication was available that reported the results at 12 months. Two publications concerned the same study. This resulted in the inclusion of 10 papers reporting nine different studies. $^{2} 2023-30$ The characteristics of these studies are shown in table 2.

The methodological quality of the selected studies is described in the table in the online supplement. The highest scores were observed for studies comparing pharmacological treatments because these studies scored positive on items about 'doubleblinding'. In studies comparing counselling with, for instance, usual care, double-blinding is not feasible so they received a lower quality score. All nine studies were included in the analyses. The table in the online supplement also shows the definitions of abstinence, the method of biochemical validation and the reported abstinence rates for the interventions in the different arms of the nine selected studies. Nineteen different estimates of 12-month continuous abstinence were reported, one estimate for usual care, ${ }^{20}$ three for minimal counselling, ${ }^{20} 2324$ six for intensive counselling ${ }^{24-29} 31$ and nine for pharmacotherapy (three for NRT, three for bupropion and three for nortriptyline). ${ }^{23-29} 31$

The weighted average 12-month continuous abstinence rates for intensive counselling $(6.0 \%)$ and for pharmacotherapy $(12.3 \%)$ were significantly higher than for usual care $(1.4 \%)$. This was not the case for minimal counselling with an abstinence rate of $2.6 \%$ (table 3 ). Six studies provided sufficient details to estimate the additional costs of the interventions, minimal counselling (three estimates ${ }^{20} 2324$ ), intensive counselling (five estimates ${ }^{24-27}$ ) and pharmacotherapy (eight estimates $^{23-27}$ ) compared with usual care. Table 3 shows the weighted average intervention costs as well as the minimum and maximum costs observed within the intervention category.

Table 4 shows the results for the base case analysis, 1 year implementation of the intervention for $50 \%$ of the patients with COPD who smoked and evaluation of outcomes over a 25 -year time horizon. Compared with usual care, the discounted cumulative number of OALYs gained among this group of patients with COPD in the Netherlands was 280 for minimal counselling, 960 for intensive counselling and 2240 for pharmacotherapy. Figure 1 shows the undiscounted number of OALYs gained per year over the 25-year time horizon of the base case analysis. For each of the interventions the maximum gain in OALYs was observed 10-15 years after implementation. Compared with usual care, the net costs (difference in intervention costs minus savings in COPD-related healthcare costs) were $€ 4.8 \times 10^{6}$ for minimal counselling, $€ 7.9 \times 10^{6}$ for intensive counselling and $€ 6.3 \times 10^{6}$ for pharmacotherapy. Estimates of the cost-effectiveness compared with usual care ranged from $€ 2400$ for pharmacotherapy to $€ 16900$ per OALY gained for minimal counselling. If each intervention was compared with the next most effective intervention, the cost per OALY of intensive versus minimal counselling was $€ 4600$, while pharmacotherapy versus intensive counselling was cost saving

\section{Uncertainty and sensitivity analyses}

Figure 2 shows the uncertainty around the difference in total costs and the difference in OALYs compared with usual care as a result of the uncertainty around the 12-month continuous abstinence rates and the intervention costs. For minimal counselling the results varied from less effective than usual care with 
Table 2 Characteristics of studies included in the review

\begin{tabular}{ll}
\hline Study & Study population \\
\hline Kotz, $2009^{23}$ & $\begin{array}{l}\text { Current smokers ( }>10 \text { pack years) wh } \\
\text { previously undetected mild/moderate } \\
\text { airflow limitation recruited from the } \\
\text { general population, aged } 35-70 \text { years } \\
\text { who were motivated to quit smoking }\end{array}$ \\
\\
Wilson, $2008^{24}$ \\
\\
Smoking COPD patients treated in an \\
outpatient respiratory centre with an \\
intention to stop smoking
\end{tabular}
intention to stop smoking
$9153 \%$ mild $\left(\mathrm{FEV}_{1}>50 \%\right), 34 \%$ moderate $\left(30 \%<\mathrm{FEV}_{1}<50 \%\right)$, $13 \%$ severe $\left(\mathrm{FEV}_{1}\right.$ $<30 \%)$

Patients with clinically treated COPD motivated to quit smoking, aged $40-75$ years, treated in the outpatient department of an hospital
Tonnesen, $2006^{26}$

Wagena, 2005/ Kaper, $2006^{27} 28$

Hilberink, $2005^{20}$
Smoking patients aged $>18$ years with a clinical diagnosis of COPD ( $\mathrm{FEV}_{1} / \mathrm{FVC}$ $<70 \%$, $\mathrm{FEV}_{1}<90 \%$ ) recruited from lung clinics who were willing to follow the study protocol
$3709 \%$ mild $\left(\mathrm{FEV}_{1}>80 \%\right), 53 \%$ moderate $\left(50 \%<\mathrm{FEV}_{1}<80 \%\right), 30 \%$ severe $(30 \%$ $\left.<\mathrm{FEV}_{1}<50 \%\right), 8 \%$ very severe COPD $\left(\mathrm{FEV}_{1}<30 \%\right)$

$14438 \%$ mild $\left(\mathrm{FEV}_{1}>80 \%\right), 56 \%$ moderate $\left(50 \%<\mathrm{FEV}_{1}<80 \%\right)$ and $6 \%$ severe COPD $\left(\mathrm{FEV}_{1}<50 \%\right)$ smoking for at least 5 years, $>10$ cigarettes per day, aged $30-70$ years who were motivated to stop smoking

Smoking COPD patients $>35$ years treated by the GP and not under control of chest physician who were willing to participate

392 Probably mild/moderate according to GOLD classification
Intervention description (intervention category*)

Treatment group: Confrontational counselling (confrontation with spirometry results) during face-to-face sessions (160 min) + one telephone session $(5-15 \mathrm{~min})$ by a respiratory nurse plus nortriptyline for 7 weeks (pharmacotherapy).

Control group 1: Face-to-face (160 min) and telephone counselling (5-15 $\mathrm{min})$ by a respiratory nurse + nortriptyline for 7 weeks (pharmacotherapy).

Control group 2: Care as usual for smoking cessation provided by the patient's own general practitioner (minimal counselling). All patients: Brief advice to stop smoking by a physician (5-10 min) + a leaflet about smoking cessation.

Group 1: Individual support: 5 individual support sessions (max $60 \mathrm{~min}$ ) by a respiratory nurse. Free NRT was offered but not compulsory (used by $59 \%$ of patients) (pharmacotherapy).

Group 2: Group support: 5 group support sessions (max $60 \mathrm{~min}$ ) by a respiratory nurse. Free NRT was offered but not compulsory (used by $41 \%$ of patients) (intensive counselling).

Group 3: Control: No further support (minimal counselling)

Group 1: Smoke Stop Therapy (SST)= group counselling (360 min), individual face-to-face (195 $\mathrm{min}$ ) and telephone counselling ( $40 \mathrm{~min}$ ) by a respiratory nurse. In case of relapse, individual sessions 'recycled'. Pharmacological support strongly advised. Bupropion provided free of charge (used by $100 \%$ of patients) (pharmacotherapy).

Group 2: LMIS=individual (150 min) and telephone counselling (30 $\mathrm{min}$ ) by a respiratory nurse. Pharmacological support used by choice on own expense (used by $41 \%$ of patients) (intensive counselling)

Low-support: Individual and telephone sessions (total $150 \mathrm{~min}$ ) by a respiratory nurse + take-home material, High support individual and telephone sessions (total $270 \mathrm{~min}$ ) by a respiratory nurse + takehome material.

Group 1: low support plus placebo (intensive counselling) Group 2: high support plus placebo (intensive counselling) Group3: low support +12 weeks NRT sublingual tablets (pharmacotherapy) Group 4: high support +12 weeks NRT sublingual tablets (pharmacotherapy) All patients: individual (total $60 \mathrm{~min}$ ) and telephone counselling sessions (total

$30 \mathrm{~min}$ ) by a respiratory nurse. Group 1: Bupropion for 12 weeks (pharmacotherapy)

Group 2: Nortriptyline for 12 weeks (pharmacotherapy)

Group 3: Placebo for 12 weeks (intensive counselling)

Group 2: care as usual delivered by the GP (usual care) 
Table 2 Continued

\begin{tabular}{|c|c|c|c|c|}
\hline Study & Study population & $\mathbf{N}$ & Severity of COPD & $\begin{array}{l}\text { Intervention description (intervention } \\
\text { category }^{*} \text { ) }\end{array}$ \\
\hline Tashkin, $2001^{2931}$ & $\begin{array}{l}\text { Current smokers with stage I or II COPD, } \\
\text { aged }>35 \text { years, smoking }>15 \\
\text { cigarettes/day for the previous year and } \\
\text { did not quit smoking }>3 \text { months in the } \\
\text { previous year who were motivated to quit } \\
\text { smoking }\end{array}$ & 404 & $\begin{array}{l}\text { Patients with stage I }\left(\mathrm{FEV}_{1} \% \text { pred }>50 \%\right) \\
\text { and stage II }\left(35 \%<\mathrm{FEV}_{1} \% \text { pred }<50 \%\right)\end{array}$ & $\begin{array}{l}\text { All patients received brief face-to-face } \\
\text { counselling at each of the } 9 \text { visits to the } \\
\text { clinic plus } 1 \text { telephone session } 3 \text { days after } \\
\text { the target quit data. } \\
\text { Group 1: bupropion (pharmacotherapy) } \\
\text { Group 2: placebo (intensive counselling) }\end{array}$ \\
\hline Brandt, $1997^{30}$ & $\begin{array}{l}\text { Smoking patients with COPD admitted to } \\
\text { the general medical ward of an hospital }\end{array}$ & 56 & $\begin{array}{l}\text { Probably severe and very severe COPD } \\
\text { according to GOLD }\end{array}$ & $\begin{array}{l}\text { All patients received the same instructions } \\
\text { on how to deal with their disease, the } \\
\text { same encouragement to stop smoking and } \\
\text { the same medical treatment. } \\
\text { Group 1: use of the word 'smokers' lung' in } \\
\text { all information material and by medical } \\
\text { staff (intensive counselling) } \\
\text { Group 2: use of the words 'chronic } \\
\text { bronchitis' or 'emphysema' (intensive } \\
\text { counselling) }\end{array}$ \\
\hline Anthonisen, $1994^{2}$ & $\begin{array}{l}\text { Smokers aged } 35-60 \text { years with an } \mathrm{FEV}_{1} / \\
\mathrm{FVC}<70 \% \text { and } 55 \%<\mathrm{FEV}_{1}<90 \%\end{array}$ & 5887 & $\begin{array}{l}55 \%<\mathrm{FEV}_{1}<90 \% \text {, mild and moderate } \\
\text { COPD according to GOLD }\end{array}$ & $\begin{array}{l}\text { Group 1: Physician message, individual } \\
\text { session with interventionist for behavioral } \\
\text { interview, group orientation meeting, } 12 \\
\text { intensive group sessions, clinic visits every } \\
4 \text { months for } 5 \text { years, maintenance } \\
\text { programme for quitters, extended } \\
\text { intervention programme for patients still } \\
\text { smoking or relapsing and NRT gum plus } \\
\text { ipatropium bromide (Atrovent) } \\
\text { (pharmacotherapy) } \\
\text { Group 2: As for group } 1+\text { placebo inhaler } \\
\text { (pharmacotherapy) } \\
\text { Group 3: Care as usual (usual care) }\end{array}$ \\
\hline
\end{tabular}

*The category pharmacotherapy refers to intensive counselling in combination with pharmacotherapy.

COPD, chronic obstructive pulmonary disease; $\mathrm{FEV}_{1}$, forced expiratory volume in $1 \mathrm{~s}$; FVC, forced vital capacity; LMIS, minimal intervention strategy for lung patients; NRT, nicotine replacement therapy; SMOCC, smoking cessation in patients with COPD in general practice.

higher costs to more effective with cost savings. The results for intensive counselling ranged from more effective and cost saving to a maximum possible cost per OALY gained of $€ 44800$, while for pharmacotherapy the results ranged from more effective and cost saving to a maximum of $€ 15700$ per OALY gained. The results of the different sensitivity analyses for all interventions compared with usual care are shown in table 4. Using the 12month point prevalence rates for each of the three types of interventions and usual care resulted in a slightly lower estimate of the cost per OALY gained for minimal counselling and slightly higher estimates for intensive counselling and pharmacotherapy versus usual care compared with the base case analysis. No discounting for both effects and costs also resulted in lower estimates of the cost per OALY gained, with pharmacotherapy even being cost saving. The third sensitivity analysis resulted in ORs of 2.4, 4.7 and 9.8 for minimal counselling, intensive counselling and pharmacotherapy, respectively, compared with usual care. Applying these to the 12-month continuous abstinence rate of usual care $(1.4 \%)$ resulted in the following abstinence rates of $3.3 \%, 6.4 \%$ and $13.2 \%$ for minimal counselling, intensive counselling and pharmcotherapy, respectively. Consequently, the cost-effectiveness of all three interventions was slightly better than the base case analysis. Outcomes based on a cohort of patients with COPD instead of using the dynamic version of the model did not have much influence on the results. The fifth sensitivity analysis based on the 12-month continuous abstinence rate and the weighted average intervention costs excluding the studies on nortriptyline (12.0\% and $€ 403$, respectively) showed an increase in the cost per OALY for pharmacotherapy compared with usual care from $€ 2400$ to $€ 6100$.

\section{DISCUSSION}

This study estimated the impact of offering different types of smoking cessation interventions to patients with COPD. Metaanalysis showed that both intensive counselling (defined as $>90$ min counselling) as well as intensive counselling with any type of pharmacotherapy were significantly more effective than usual care. The cost-effectiveness ratios for both types of intervention were low and below $€ 20000$ per OALY gained, the

Table 3 Combined abstinence rates for the four interventions groups and associated intervention costs

\begin{tabular}{|c|c|c|c|c|c|}
\hline & \multicolumn{2}{|c|}{ 12-month continuous abstinence rates* } & \multicolumn{2}{|c|}{ 12-month point prevalence rates* } & \multirow[b]{2}{*}{$\begin{array}{l}\text { Weighted } \dagger \text { average intervention } \\
\text { costs } 2007, € \neq(\min -\text { max })\end{array}$} \\
\hline & $\begin{array}{l}\text { Average } \\
\text { rate }\end{array}$ & $\begin{array}{l}\text { Difference with usual } \\
\text { care }(95 \% \mathrm{CI})\end{array}$ & $\begin{array}{l}\text { Average } \\
\text { rate }\end{array}$ & $\begin{array}{l}\text { Difference with usual } \\
\text { care }(95 \% \mathrm{CI})\end{array}$ & \\
\hline Usual care & $1.4 \%$ & - & $6.8 \%$ & - & 0 \\
\hline Minimal or brief counselling $<90 \mathrm{~min}$ & $2.6 \%$ & $1.2 \%(-1.3 \%$ to $3.7 \%)$ & $9.0 \%$ & $2.2 \%(-3.4 \%$ to $7.7 \%)$ & $89(22-112)$ \\
\hline Intensive counselling $\geq 90 \mathrm{~min}$ & $6.0 \%$ & $4.6 \%(1.8 \%$ to $7.4 \%)$ & $12.3 \%$ & $5.5 \%(-1.6 \%$ to $12.6 \%)$ & $205(93-264)$ \\
\hline $\begin{array}{l}\text { Intensive counselling } \geq 90 \text { min with } \\
\text { pharmacotherapy }\end{array}$ & $12.3 \%$ & $10.9 \%(6.9 \%$ to $15.0 \%)$ & $19.0 \%$ & $12.2 \%(0.5 \%$ to $23.9 \%)$ & $305(130-452)$ \\
\hline
\end{tabular}

\footnotetext{
*Based on random effect meta-analysis performed on the absolute abstinence rates in trial arms.

+Weighted by number of patients in the study.

$\ddagger$ Calculated based on resource use as described in the individual papers valued using the following unit costs: general practitioner $€ 2.10 /$ min, respiratory physician $€ 5.90 /$ min, respiratory nurse
} $€ 0.90$ /min, information material $€ 1.00,12$ weeks NRT patches $€ 194,12$ weeks NRT tablets $€ 190,12$ weeks NRT gum $€ 178$, bupropion $€ 1.30 /$ tablet, nortriptyline $€ 0.16 /$ tablet. 
Table 4 Results of the base case and sensitivity analyses $(€, 2007)$ : 1-year implementation of minimal counselling, intensive counselling or intensive counselling in combination with pharmacotherapy ('pharmacotherapy') compared with usual care, time horizon 25 years*

\begin{tabular}{|c|c|c|c|c|c|c|c|c|}
\hline Intervention & $\begin{array}{l}\text { Type of analysis: base case } \\
\text { or sensitivity analysis (SA) }\end{array}$ & $\begin{array}{l}\text { Life-years } \\
\text { gained }\end{array}$ & $\begin{array}{l}\text { OALYs } \\
\text { gained }\end{array}$ & $\begin{array}{l}\text { Reduction in } \\
\text { mortality } \dagger\end{array}$ & $\begin{array}{l}\text { Difference in } \\
\text { intervention costs } \\
\left(€ \times 10^{6}\right)\end{array}$ & $\begin{array}{l}\text { Savings in } \\
\text { COPD-related costs } \\
\left(€ \times 10^{6}\right)\end{array}$ & $\begin{array}{l}\text { Cost per life } \\
\text { year gained } \\
(€)\end{array}$ & $\begin{array}{l}\text { Cost per } \\
\text { QALY gained } \\
(€)\end{array}$ \\
\hline \multirow{5}{*}{$\begin{array}{l}\text { Minimal } \\
\text { counselling }\end{array}$} & Base case analysis & 210 & 280 & 90 & 6.8 & 2.0 & 22400 & 16900 \\
\hline & SA1: 12-month point prevalence rates & 210 & 300 & 160 & 6.8 & 2.5 & 20900 & 14400 \\
\hline & SA2: No discounting & 260 & 340 & 100 & 6.8 & 3.0 & 14300 & 11000 \\
\hline & SA3: Network meta-analysis & 310 & 420 & 150 & 6.8 & 3.1 & 11800 & 8800 \\
\hline & SA4: Cohort instead of dynamic & 200 & 260 & 100 & 6.8 & 1.9 & 24600 & 18200 \\
\hline \multirow[t]{5}{*}{ Intensive counselling } & Base case analysis & 690 & 960 & 340 & 15.6 & 7.6 & 11600 & 8200 \\
\hline & SA1: 12-month point prevalence rates & 600 & 810 & 280 & 15.6 & 5.9 & 16200 & 11900 \\
\hline & SA2: No discounting & 850 & 1160 & 380 & 15.6 & 11.5 & 4800 & 3500 \\
\hline & SA3: Network meta-analysis & 750 & 1050 & 370 & 15.6 & 8.3 & 9600 & 6900 \\
\hline & SA4: Cohort instead of dynamic & 680 & 950 & 390 & 15.6 & 7.4 & 12000 & 8600 \\
\hline \multirow[t]{6}{*}{ Pharmacotherapy } & Base case analysis & 1590 & 2240 & 830 & 23.2 & 17.9 & 3300 & 2400 \\
\hline & SA1: 12-month point prevalence rates & 1260 & 1740 & 630 & 23.2 & 13.0 & 8000 & 5800 \\
\hline & SA2: No discounting & 1960 & 2690 & 910 & 23.2 & 26.8 & Cost saving & Cost saving \\
\hline & SA3: Network meta-analysis & 1710 & 2400 & 920 & 23.3 & 19.2 & 2300 & 1600 \\
\hline & SA4: Cohort instead of dynamic & 1550 & 2170 & 850 & 23.2 & 17.1 & 3900 & 2800 \\
\hline & SA5: Excluding studies with nortriptyline & 1570 & 2190 & 820 & 30.6 & 17.3 & 8500 & 6100 \\
\hline
\end{tabular}

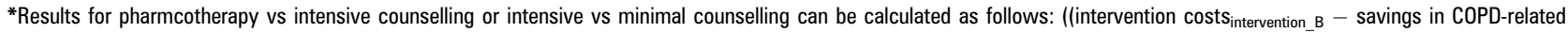
cost $\left._{\text {intervention B }}\right)-\left(\left(\right.\right.$ intervention costs $s_{\text {intervention } A}-$ savings in COPD-related cost $\left.\left.t_{\text {intervention } A}\right)\right) /\left(Q A L Y s_{\text {intervention B }}-0 A L Y s_{\text {intervention A }}\right)$.

†Number of deaths avoided over the time horizon of the analyses.

COPD, chronic obstructive pulmonary disease; QALY, quality-adjusted life years.

often used threshold for an intervention to be considered costeffective in the Netherlands. ${ }^{32}$ Comparison of pharmacotherapy with intensive counselling resulted in cost savings, making pharmacotherapy the most favourable intervention. The cost per OALY gained for minimal or brief counselling (defined as counselling for $<90 \mathrm{~min}$ ) was also below $€ 20000$, but the effectiveness was not significantly different from usual care.

Our literature search on studies reporting the effectiveness of smoking cessation interventions in patients with COPD resulted in nine studies. It was therefore impossible to group the interventions into more than three or four categories, although we acknowledge that differences in methods and interventions within one category existed. Minimal and intensive counselling are commonly used classifications in smoking cessation studies and reviews. The pharmacotherapy category was too small to subdivide by type, intensity or duration of pharmacotherapy. Longer duration or greater intensity of pharmacotherapy would probably lead to higher abstinence rates, although it is not clear

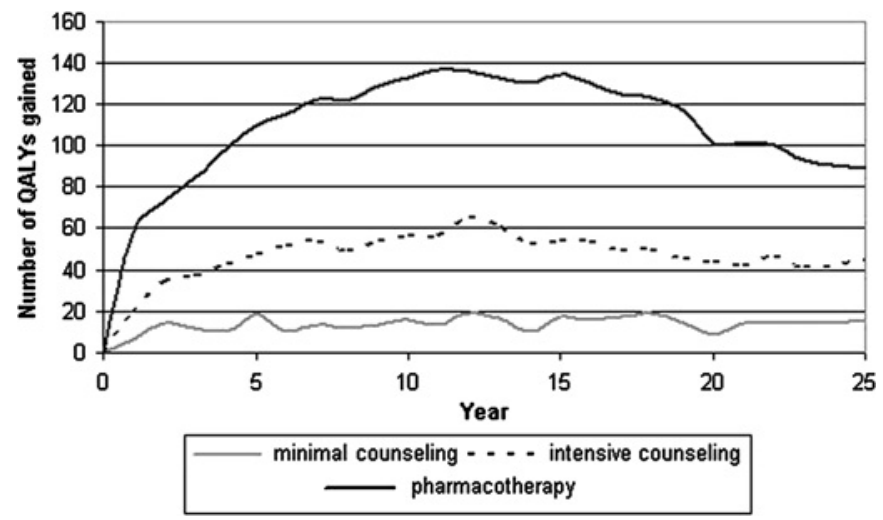

Figure 1 Annual number of quality-adjusted life years (QALYs) gained over time for 1-year implementation of minimal or brief counselling, intensive counselling without pharmacotherapy and intensive counselling with pharmacotherapy ('pharmacotherapy') compared with usual care, $0 \%$ discounting. whether this is also true for patients with COPD. With regard to type of pharmacotherapy, the meta-analysis included three estimates on each type of pharmacotherapy (bupropion, nortriptyline and NRT). If, despite the low numbers, the category pharmacotherapy was subdivided into intensive counselling plus NRT and intensive counselling plus antidepressant, the cost per OALY gained would have been $€ 10400$ for NRT and $€ 600$ for antidepressants, both low ratios. However, more research on the effectiveness of pharmacotherapies in patients with COPD is needed to give better estimates of the cost-effectiveness specified by type, intensity of supportive counselling and duration of pharmacotherapy. Our estimate of pharmacotherapy included the results of studies offering pharmacotherapy on a non-compulsory basis if this was used by more than $50 \%$ of the patients. This might have resulted in a potential underestimation of the effect of pharmacotherapy. Exclusion of the two trials with non-compulsory pharmacotherapy, however, only had a small

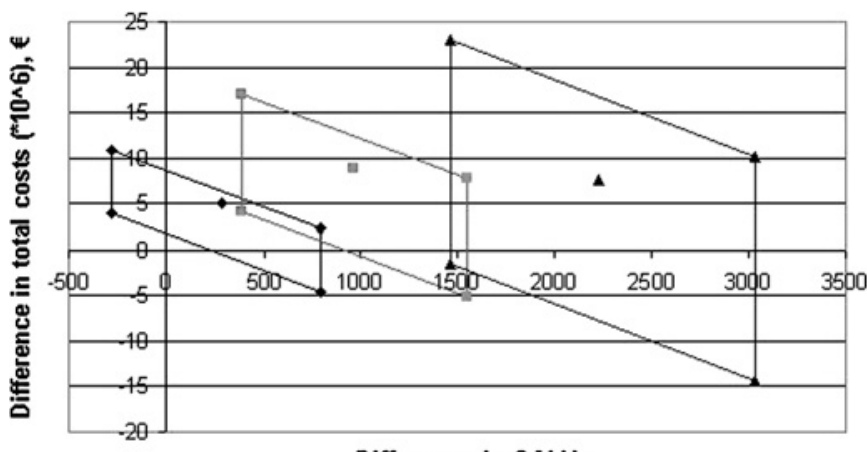

Difference in QALYs

Figure 2 Uncertainty concerning the difference in total costs and the difference in quality-adjusted life years (OALYs) for the base case analysis, 1 year implementation of the intervention compared with usual care over a time horizon of 25 years, discount rate for effects $1.5 \%$ and for costs $4 \%$. Diamond, minimal or brief counselling; square, intensive counselling; triangle, intensive counselling plus pharmacotherapy. 
effect on the incremental cost-effectiveness ratio of pharmacotherapy (€1900 instead of $€ 2400$ per OALY gained).

Our estimates of the 12-month continuous abstinence rates of intensive counselling $(6.0 \%)$ and pharmacotherapy $(12.3 \%)$ were still relatively low and lower than observed in the general population (10\% and $17 \%$, respectively). ${ }^{33} 34$ These results suggest that abstinence rates in patients with COPD are lower than in 'healthy' smokers. This finding was also observed in a study by Wagena et al which showed that patients with COPD had a 30\% higher chance of relapsing than smokers at risk of COPD. ${ }^{27}$ By increasing the intensity and duration of counselling and/or pharmacotherapy, the abstinence rates in COPD may possibly increase, as shown by the Lung Health Study also included in our meta-analysis. ${ }^{2}$ This study is unique in terms of intensity of the intervention, monitoring of patients and followup, which resulted in remarkably high abstinence rates for the smoking intervention group but also for the usual care group. Although the current guidelines advocate the most intensive smoking cessation intervention, it is questionable whether an intervention with such a high intensity as the Lung Health Study is feasible in daily practice.

Results for the cost-effectiveness of pharmacotherapy and intensive counselling in COPD were comparable with the cost per OALY gained for smoking cessation support in the general population. For the general population studies on NRT, bupropion and nortriptyline have shown cost-effectiveness ratios consistently below $€ 10000$ per (quality adjusted) life year. ${ }^{12} 35-38$ The cost-effectiveness ratio for minimal counselling in COPD is somewhat higher than in studies in the general public. ${ }^{11}{ }^{12}$ This is probably a result of the lower abstinence rate and the relatively high intervention costs compared with other studies on minimal counselling. In our study, minimal counselling for patients with COPD consisted of an average of about 25 min counselling while, in most general population studies, minimal counselling is defined as $<10$ min of cessation advice.

The common approach in reviews evaluating the effectiveness of smoking cessation interventions is to report the RR or OR of one comparator with the other. ${ }^{933} 34$ The best method to retain randomisation would be a network meta-analysis. However, in addition, for a cost-effectiveness analysis the absolute quit rate for at least one of the interventions or usual care needs to be estimated. We decided instead to use the averages of the absolute quit rates as obtained from random effects meta-analysis in our base case analysis. Estimating ORs and applying them to the absolute quit rate of usual care would have resulted in a slightly more favourable cost per OALY estimates for all interventions, but would not have changed the conclusions much (see third sensitivity analysis).

In conclusion, compared with usual care, implementation of intensive counselling with and without pharmacotherapy for patients with COPD resulted in low costs per OALY gained with ratios in the range of results presented for smoking cessation support in the general population. Implementation of minimal counselling was also cost-effective, but the effectiveness was not significantly different from usual care. Pharmacotherapy in combination with intensive counselling was cost saving compared with intensive counselling alone and dominated the other interventions. These results confirm the advice given in the guidelines that patients with COPD should be offered the most intensive smoking cessation intervention feasible, not only from a clinical but also from an economic perspective.

Acknowledgements The authors acknowledge the help of Maiwenn Al with the statistical analyses.
Funding This study was financially supported by the Dutch Government (Ministry of Health).

Competing interests $\mathrm{MH}$ has participated in smoking cessation research that is financially supported by the pharmaceutical industry. TF is an employee of the Dutch National Institute for Public Health and the Environment and also works on a project granted by the Dutch National Asthma Foundation to develop a simulation model of COPD. MR-VM participates in smoking cessation research that is financially supported by the pharmaceutical industry and also acts as a consultant on smoking cessation issues. $\mathrm{RH}$ has no conflicts of interest.

Provenance and peer review Not commissioned; externally peer reviewed.

\section{REFERENCES}

1. Petty TL. COPD in perspective. Chest 2002;121(Suppl 5):116-20S.

2. Anthonisen NR, Connett JE, Kiley JP, et al. Effects of smoking intervention and the use of an inhaled anticholinergic bronchodilator on the rate of decline of $\mathrm{FEV}_{1}$. The Lung Health Study. JAMA 1994;272:1497-505.

3. Burchfiel CM, Marcus EB, Curb JD, et al. Effects of smoking and smoking cessation on longitudinal decline in pulmonary function. Am J Respir Crit Care Med 1995; 151:1778-85

4. Scanlon PD, Connett JE, Waller LA, et al. Smoking cessation and lung function in mild-to-moderate chronic obstructive pulmonary disease. The Lung Health Study. Am J Respir Crit Care Med 2000;161(2 Pt 1):381-90.

5. Pride NB. Smoking cessation: effects on symptoms, spirometry and future trends in COPD. Thorax 2001;56(Suppl 2):ii7-10.

6. Jansson SA, Andersson F, Borg S, et al. Costs of COPD in Sweden according to disease severity. Chest 2002;122:1994-2002.

7. Jenkins C. COPD management. Part I. Strategies for managing the burden of established COPD. Int J Tuberc Lung Dis 2008;12:586-94.

8. Rodriguez Roisin R, Rabe KF, Anzueto A, et al. Global initiative for chronic obstructive lung disease. Workshop Report: Global Strategy for the Diagnosis, Management and Prevention of COPD: updated 2008. 2008. http://www.goldcopd com/ (accessed Mar 2009).

9. Wagena EJ, van der Meer RM, Ostelo RJ, et al. The efficacy of smoking cessation strategies in people with chronic obstructive pulmonary disease: results from a systematic review. Respir Med 2004;98:805-15.

10. Strassmann R, Bausch B, Spaar A, et al. Smoking cessation interventions in COPD: a network meta-analysis of randomised trials. Eur Respir J 2009; 34:634-40.

11. Parrott S, Godfrey C, Raw M, et al. Guidance for commissioners on the cost effectiveness of smoking cessation interventions. Health Educational Authority. Thorax 1998;53(Suppl 5 Pt 2):S1-38.

12. Feenstra TL, Hamberg-van Reenen HH, Hoogenveen RT, et al. Cost-effectiveness of face-to-face smoking cessation interventions: a dynamic modeling study. Value Health 2005;8:178-90.

13. Hoogendoorn M, Rutten-van Molken MP, Hoogenveen RT, et al. A dynamic population model of disease progression in COPD. Eur Respir J 2005; 26:223-33.

14. Jadad AR, Moore RA, Carroll D, et al. Assessing the quality of reports of randomized clinical trials: is blinding necessary? Control Clin Trials 1996;17:1-12.

15. Verhagen AP, de Vet HC de Bie RA, et al. The Delphi list: a criteria list for quality assessment of randomized clinical trials for conducting systematic reviews developed by Delphi consensus. J Clin Epidemiol 1998:51:1235-41.

16. Higgins JP, Thompson SG, Deeks JJ, et al. Measuring inconsistency in metaanalyses. BMJ 2003;327:557-60.

17. Hoogendoorn M, Feenstra TL, Schermer TR, et al. Severity distribution of chronic obstructive pulmonary disease (COPD) in Dutch general practice. Respir Med 2006;100:83-6.

18. Borg S, Ericsson A, Wedzicha J, et al. A computer simulation model of the natura history and economic impact of chronic obstructive pulmonary disease. Value Health 2004;7:153-67.

19. Jimenez-Ruiz CA, Masa F, Miravitlles M, et al. Smoking characteristics: differences in attitudes and dependence between healthy smokers and smokers with COPD. Chest 2001;119:1365-70

20. Hilberink SR, Jacobs JE, Bottema BJ, et al. Smoking cessation in patients with COPD in daily general practice (SMOCC): six months' results. Prev Med 2005:41:822-7.

21. Rodenburg-van Dieten HEM. Guidelines for pharmaco-economic research. Diemen, The Netherlands: Dutch Health Care Insurance Board, 2005.

22. Higgins JP, Whitehead A. Borrowing strength from external trials in a metaanalysis. Stat Med 1996;15:2733-49.

23. Kotz D, Wesseling G, Huibers MJ, et al. Efficacy of confronting smokers with airflow limitation for smoking cessation. Eur Respir J 2009;33:754-62.

24. Wilson JS, Fitzsimons D, Bradbury I, et al. Does additional support by nurses enhance the effect of a brief smoking cessation intervention in people with moderate to severe chronic obstructive pulmonary disease? A randomised controlled trial. Int J Nurs Stud 2008;45:508-17.

25. Christenhusz L, Pieterse M, Seydel E, et al. Prospective determinants of smoking cessation in COPD patients within a high intensity or a brief counseling intervention. Patient Educ Couns 2007:66:162-6. 
26. Tonnesen P, Mikkelsen K, Bremann L. Nurse-conducted smoking cessation in patients with COPD using nicotine sublingual tablets and behavioral support. Chest 2006:130:334-42.

27. Wagena EJ, Knipschild PG, Huibers MJ, et al. Efficacy of bupropion and nortriptyline for smoking cessation among people at risk for or with chronic obstructive pulmonary disease. Arch Intern Med 2005:165:2286-92.

28. Kaper J. Smoking cessation treatment and its reimbursement. Maastricht: University of Maastricht, 2006. http://arno.unimaas.nl/show.cgi?fid=5377 (accessed Oct 2007).

29. Tashkin D, Kanner R, Bailey W, et al. Smoking cessation in patients with chronic obstructive pulmonary disease: a double-blind, placebo-controlled, randomised trial. Lancet 2001;357:1571-5.

30. Brandt CJ, Ellegaard $H$, Joensen $M$, et al. Effect of diagnosis of "smoker's lung". RYLUNG Group. Lancet 1997;349:253.

31. Jarvis MJ, Powell SR, Marsh HS, et al. A meta-analysis of clinical studies confirms the effectiveness of bupropion SR (Zyban) in smoking cessation. Poster presentation at the 8th Annual Meeting of the Society for Research on Nicotine and Tobacco. Savannah, Georgia, 2002.
32. Casparie AF, van Hout BA, Simoons ML. Guidelines and costs. Ned Tijdschr Geneeskd 1998;142:2075-7.

33. Hughes J, Stead L, Lancaster T. Antidepressants for smoking cessation. Cochrane Database Syst Rev 2007:(1):CD000031.

34. Stead LF, Perera R, Bullen C, et al. Nicotine replacement therapy for smoking cessation. Cochrane Database Syst Rev 2008;(1):CD000146.

35. Bolin K, Lindgren B, Willers S. The cost utility of bupropion in smoking cessation health programs: simulation model results for Sweden. Chest 2006;

129:651-60.

36. Hall SM, Lightwood JM, Humfleet GL, et al. Cost-effectiveness of bupropion, nortriptyline, and psychological intervention in smoking cessation. J Behav Health Serv Res 2005;32:381-92.

37. Stapleton JA, Lowin A, Russell MA. Prescription of transdermal nicotine patches for smoking cessation in general practice: evaluation of cost-effectiveness. Lancet 1999:354:210-15

38. Song F, Raftery J, Aveyard P, et al. Cost-effectiveness of pharmacological interventions for smoking cessation: a literature review and a decision analytic analysis. Med Decis Making 2002;22(Suppl 5):S26-37.

\section{Lung alert}

\section{CPAP can be considered as an alternative to intubation and surfactant treatment in extremely preterm infants}

In this study of 1316 infants born 24-27 weeks and 6 days gestation, extremely low weight infants were randomised to receive continuous positive airway pressure (CPAP) treatment in the delivery room or intubation and surfactant treatment $<1 \mathrm{~h}$ after birth.

The primary outcome of death was not significantly different between treatment groups. Rates of bronchopulmonary dysplasia (supplemental oxygen requirement at 36 weeks) were also not significantly different. Secondary outcomes in this study showed that infants receiving CPAP treatment required significantly less intubation or postnatal corticosteroids for bronchopulmonary dysplasia and fewer mechanically ventilated days. Infants treated with CPAP were also more likely to be alive and off mechanical ventilation by day 7 , with no other significantly different adverse outcomes between groups.

This multicentre trial strongly suggests that CPAP in the delivery room can be considered as an alternative to intubation and surfactant treatment without jeopardising extremely preterm infant outcome.

- Finer NN, Carlo WA, Walsh MC, et al: SUPPORT Study Group of the Eunice Kennedy Shriver NICHD Neonatal Research Network. Early CPAP versus surfactant in extremely preterm infants. N Engl J Med 2010;362:1970-9.

\section{J L Bacon}

Correspondence to J L Bacon, East Surrey Hospital, Redhill, Surrey, UK; jenny.bacon@sash.nhs.uk Thorax 2010;65:718. doi:10.1136/thx.2010.145680 